\title{
Um Relato das Percepções dos Alunos sobre o Desenvolvimento de Tecnologias Aplicadas a Produtos Educacionais
}

\author{
Emanuel Ferreira Coutinho, Universidade Federal do Ceará - Campus Quixadá, \\ emanuel.coutinho@ufc.br, 0000-0003-2233-7109 \\ José Gilvan Rodrigues Maia, Universidade Federal do Ceará - UFC Virtual, \\ gilvanmaia@virtual.ufc.br, 0000-0002-2607-2729
}

Resumo: A sociedade atualmente utiliza tecnologias digitais em diversas áreas do conhecimento, impactando pessoas e organizações. Uma área que demanda novas tecnologias digitais é a Educação, em seus mais variados níveis. O ensino de qualquer disciplina técnica constitui um conjunto de atividades desafiantes para o docentes e discentes, e desenvolver uma aplicação ou serviço pode ser bastante complexo para quem não possui formação na área de programação. O objetivo deste trabalho é analisar as percepções dos alunos durante uma disciplina de desenvolvimento de aplicações educacionais. Para isto, um questionário foi aplicado e analisado quantitativamente e qualitativamente. As principais conclusões deste trabalho foram: reconhecimento da dificuldade no desenvolvimento para quem não possui formação em programação, necessidade de se gerenciar bem a disciplina para que a metodologia seja eficaz, e percepção dos alunos diante de prazos para entrega dos produtos.

Palavras Chaves: aplicações, desenvolvimento, análise qualitativa.

\section{A Report of Students' Perceptions on the Development of Technologies Applied to Educational Products}

Abstract: Society currently uses digital technologies in various areas of knowledge, impacting people and organizations. An area that demands new digital technologies is Education, at its most varied levels. Teaching of any technical discipline constitutes a set of challenging activities for professors and students, and developing an application or service can be quite complex for those who do not have a background in the area of programming. The objective of this work is to analyze the perceptions of students during a development of educational applications course. For this, a questionnaire was applied and analyzed quantitatively and qualitatively. The main conclusions were: recognition of the difficulty in development for those who do not have a background in programming, need to manage the course well so that the methodology is effective, and students' perception of deadlines.

Keywords: applications, development, qualitative analysis.

\section{Introdução}

Atualmente tecnologias são utilizadas para os mais diversos fins em virtualmente todas as áreas do conhecimento. Exemplos de tecnologias podem ser aplicações para gerenciamento de pessoas e processos, jogos que envolvem hardware e software, e dispositivos que auxiliam em algum tarefa manual ou compensam deficiências físicas.

A sociedade está em constante reconstrução, impactando significativamente organizações, especialmente em relação à dinâmica, flexibilidade e inovação para atender às suas demandas (Michels et al., 2019). Isso possui relação direta com tecnologias, e especialmente hoje, com tecnologias digitais, as quais envolvem aplicações de software.

Uma área que faz amplo uso das tecnologias digitais é a Educação, nos seus mais variados níveis. A cada ano aumenta a quantidade de tecnologias digitais que fazem parte 
do nosso cotidiano, possibilitando também o seu uso no âmbito escolar (Sonego et al., 2020). Desse modo, percebe-se que há a necessidade de explorar, criar materiais e manipular dispositivos desde a formação inicial, para que o professor tenha subsídios teórico-práticos que, posteriormente, possam ser implementados em sua prática docente.

$\mathrm{O}$ ensino de qualquer disciplina técnica constitui um conjunto de atividades desafiantes para o docente, tanto pelo constante surgimento de novas tecnologias e ferramentas, quanto pela busca por estratégias para se ajustar às novas práticas de aquisição de conhecimento adotadas pelos aprendizes atuais (Coutinho et al., 2016). Também há o desafio de relacionar a teoria com a prática para os alunos, pois geralmente eles ingressam nos cursos de graduação com perfis e níveis de conhecimento variados. Nesse contexto, disciplinas que pretendem alinhar teoria com prática são normalmente muito difíceis de se conduzir devido à necessidade de se tratar fatores técnicos (linguagens de programação, componentes, ferramentas, etc) e humanos (disponibilidade, comunicação, gestão, etc), tudo ao mesmo tempo (Coutinho et al., 2016). Além disso, a tarefa de motivar os alunos e os próprios professores está longe de ser trivial, se verificando particularmente em disciplinas de primeiro ano de cursos de graduação. Isto se deve ao fato que os conteúdos abordados muitas vezes são novidade para os alunos, constituindo um desafio para eles.

A Informática na Educação, como campo formativo, tornou-se objeto de busca de vários profissionais, não apenas daqueles da área da Educação, mas também aqueles “migrantes" de outros campos disciplinares do conhecimento (Fontoura, 2019). Sendo assim, esta área é uma oportunidade para o desenvolvimento de tecnologias educacionais, sejam aplicações, sejam abordagens ou dispositivos físicos para o ensino. Além disso, a algum tempo os atores envolvidos no ensino-aprendizagem têm usado as Tecnologias Digitais de Informação e Comunicação (TDIC) para potencializar suas ações (Almeida, Júnior, 2020). O desenvolvimento de aplicações possui suas complexidades específicas, o que pode ser um empecilho para quem não é de formação de um curso como Ciência da Computação, Sistemas de Informação ou Engenharia de Software, ou cursos relacionados. Mesmo com diversas ferramentas para facilitar a programação, tais como o Scratch e APP Inventor, o desenvolvimento de aplicações não é uma atividade tão trivial.

O objetivo deste trabalho é analisar as percepções de alunos de uma disciplina durante o desenvolvimento de aplicações educacionais. $O$ trabalho focou mais na experiência em desenvolvimento, e não na qualidade da aplicação. Para isto, um questionário foi aplicado a uma turma de mestrado e os resultados analisados por meio de procedimentos de Grounded Theory (Corbin, Strauss, 2014). Como contribuição principal deste trabalho, tem-se um relato de experiências no desenvolvimento de aplicações educacionais. As principais conclusões deste trabalho foram: reconhecimento da dificuldade no desenvolvimento para quem não possui formação em programação, necessidade de se gerenciar bem a disciplina para que a metodologia seja eficaz, e percepção dos alunos diante da pressão pelo cumprimento dos prazos para a entrega dos produtos. Este trabalho encontra-se dividido nas seguintes seções além desta introdução: na Seção 2 alguns trabalhos relacionados são discutidos; a Seção 3 apresenta os materiais e métodos aplicados ao trabalho; na Seção 4 são expostos os resultados e apresentadas algumas discussões; e por fim, a Seção 5 apresenta as conclusões e trabalhos futuros.

\section{Trabalhos Relacionados}

Diversos trabalhos na literatura relataram experiências no desenvolvimento de aplicações por indivíduos que não possuíram em sua formação práticas em programação.

Coutinho et al. (2016) relataram uma abordagem baseada em design thinking para 
o desenvolvimento de produtos e serviços envolvendo software. A intenção foi aplicar conceitos de Engenharia de Software juntamente com as ideias de design thinking. Para a obtenção de um feedback sobre a abordagem, uma avaliação do trabalho foi realizada com os alunos da disciplina, onde concluiu-se que a utilização da abordagem colaborou para a melhoria da comunicação, documentação e acompanhamento dos projetos.

Guarda et al. (2019) apresentaram uma estratégia metodológica para o ensino de lógica de programação e raciocínio lógico com o uso dos aplicativos Silent Teacher Hour of Code e Scratch, que foram utilizados para treinamento e práticas de exercícios na composição da construção do conhecimento embasado pela teoria dos 4P's da Aprendizagem Criativa no âmbito escolar. A ideia foi motivar crianças e adolescentes a aprenderem conteúdos de computação que envolvem programação, lógica e assuntos relacionados de maneira criativa para ser possível formar cidadãos críticos e ativos em uma sociedade em constante transformação. A experiência aplicada para abordagem dos conteúdos iniciais do projeto foi considerada exitosa, possibilitando a equipe do projeto mapear indicativos que auxiliaram de forma significativa as ações e atividades futuras.

Michels et al. (2019) propuseram um modelo para compreensão do processo cognitivo de construção de estratégias educacionais pelos docentes, sendo a pesquisa exploratória e qualitativa. O modelo foi desenvolvido a partir da análise das vivências de docentes em duas arquiteturas pedagógicas aplicadas na formação continuada online SOS Professor. O modelo mostra um processo cognitivo, evolutivo e não-linear que, de acordo com a abordagem relacional/interacionista, o sujeito sempre constrói conhecimento a partir de suas experiências anteriores e de novos desafios que surgem.

Souza et al. (2019) apresentaram a experiência do desenvolvimento de aplicativos para a educação pública por alunos do ensino médio em parceria com graduandos. $\mathrm{O}$ principal objetivo do projeto foi proporcionar a autoria dos estudantes como estratégia para a construção do conhecimento. Os aplicativos trabalhados foram o TripQuest e CartoGráfico, sendo interdisciplinares e podem favorecer a aprendizagem de forma lúdica. Esta experiência demonstrou que é possível criar espaços de autoria para que os jovens das escolas públicas não sejam meros reprodutores e usuários do que já está produzido, mas produtores, autores de conteúdos educacionais.

Almeida e Júnior (2020) relataram o uso da técnica colaborativa chamada Grupo de Verbalização/Grupo de Observação, junto à Suíte Google. A técnica foi aplicada em um curso superior de tecnologia com alunos da disciplina de Algoritmos II. Concluiu-se que a transposição da técnica para uso com TDIC trouxe benefícios especialmente quanto à organização espacial dos discentes. A análise dos dados coletados junto aos alunos indicou aceitação e relevância no uso da técnica em sala de aula/laboratório.

Bastos e Siqueira (2020) investigaram como tecnologia, design thinking e Experiência do Usuário podem promover a integração das práticas docentes com a realidade dos alunos, por meio de uma abordagem qualitativa e pesquisa-formação. A partir da análise do discurso dos cursistas em fóruns de discussão e relatórios textuais, os autores apresentaram o resultado da construção de conhecimento em relação a estes três itens, destacando trechos dos relatos com reflexões e possíveis mudanças nos conteúdos, práticas pedagógicas e sujeitos em formação. Os principais impactos destacados foram: regaste da motivação de professores e alunos; construção de conhecimento de forma crítica e criativa; e aprendizagem mais significativa e centrada no estudante.

Sonego et al. (2020) apresentaram a construção de aplicativos educacionais na formação de professores como uma possibilidade de uso dos dispositivos móveis em sala de aula para o desenvolvimento da m-learning. Para isso, foi aplicada uma abordagem qualitativa e quantitativa. Quatro aplicativos foram apresentados, desenvolvidos por 
docentes em formação inicial e que se tornam importantes ferramentas com potencial para dinamizar a construção do conhecimento por meio de materiais digitais.

Para comparar os trabalhos relacionados, foram definidos os seguintes critérios: (i) desenvolveu aplicativo (sim ou não); (ii) tipo de aplicação (geral, educacional, jogo, etc); (iii) tipo de plataforma (web, móvel, ambas, etc); e (iv) ferramenta (Scratch, APP Inventor, etc). A Tabela 1 apresenta os trabalhos relacionados e os critérios.

Tabela 1 - Comparação dos trabalhos relacionados (desenvolveu aplicativo, tipo de aplicação, tipo de plataforma, ferramenta).

\begin{tabular}{|l|l|l|l|l|}
\hline Trabalho & App & Tipo & Plataforma & Ferramenta \\
\hline Coutinho et al. (2016) & Sim & Jogos, Aplicações, Vídeos & Móvel, Web & Diversas plataformas \\
\hline Guarda et al. (2019) & Sim & Aplicações & Web & Hour of Code, Scratch \\
\hline Michels et al. (2019) & Não & Não se aplica & Não se aplica & Não se aplica \\
\hline Souza et al. (2019) & Sim & Jogo educativo & Móvel & App Inventor, Unity \\
\hline Almeida e Júnior (2020) & Não & Não se aplica & Web & Google Suíte \\
\hline Bastos e Siqueira (2020) & Não & Fórum & Web & Moodle \\
\hline Sonego et al. (2020) & Sim & Aplicativos educacionais & Móvel & Fábrica de Aplicativos \\
\hline
\end{tabular}

Nem todos os trabalhos citados desenvolveram aplicações, e nem todas foram de caráter educacional. Este trabalho apresenta alguns dos produtos educacionais produzidos em uma disciplina, além das percepções dos alunos. Alguns trabalhos conduziram análises qualitativas, mas nenhum utilizou uma análise qualitativa com Grounded Theory. Em nosso trabalho, aplicações educacionais são desenvolvidas em plataformas web e móvel, lançando mão de diversas ferramentas voltadas para o desenvolvimento.

\section{Material e Métodos}

O objetivo desta pesquisa é analisar quantitativamente e qualitativamente as percepções de alunos no desenvolvimento de tecnologias para a educação. Os resultados foram obtidos a partir de um questionário online aplicado aos alunos de uma turma de mestrado profissional, da disciplina Desenvolvimento de Tecnologias Aplicadas à Educação (DTAE). Esta pesquisa é de caráter exploratório. Segundo Gil (2008), pesquisas exploratórias têm como objetivo proporcionar maior familiaridade com o problema, visando torná-lo mais explícito ou construir hipóteses. Estas pesquisas também almejam o aprimoramento de ideias ou a descoberta de intuições. Seu planejamento é, portanto, bastante flexível, de modo que possibilite a consideração dos mais variados aspectos relativos ao fato estudado. Quanto à análise dos dados, esta será qualitativa.

A disciplina de DTAE tem como objetivo promover o desenvolvimento de soluções tecnológicas aplicadas à Educação. Por exemplo, aplicações web ou móvel aplicadas à Educação, jogos digitais para o ensino de alguma ciência, e dispositivos (sensores ou atuadores) que busquem uma interação entre alunos e uma temática. Notese que o produto desenvolvido pode ser direcionado para qualquer nível escolar. A disciplina possui a seguinte ementa: metodologias, técnicas e tecnologias para a especificação, construção e validação de soluções digitais educacionais; considerações acerca de ferramentas de prototipagem, autoria e desenvolvimento de soluções digitais educacionais; e experimentos na geração de soluções digitais educacionais em diversos suportes e mídias: aplicações desktop, aplicativos para dispositivos móveis, websites e serviços online, jogos eletrônicos, sistemas de computação física, realidade virtual, realidade aumentada, modelos de interfaces alternativas com usuários e outros.

O questionário foi composto por (a) questões demográficas, para se identificar o perfil do aluno, (b) questões sobre a disciplina, para se identificar seu contexto e relação com disciplinas pré-requisitos, e (c) questões abertas, de texto livre, para o aluno expor sua opinião sobre os pontos fortes e fracos da disciplina em questão e apontar possíveis V. $19 \mathrm{~N}^{\mathrm{o}}$ 2, Dezembro, 2021 DOI: https://doi.org/10.22456/1679-1916.121224 RENOTE 
melhorias. A Tabela 2 expõe as questões do questionário.

Tabela 2 - Questões do questionário online (QD = questão demográfica, QC = questão de conteúdo relacionada à disciplina, QA = questão de opinião com texto livre).

\begin{tabular}{|l|l|}
\hline QD01 & Qual seu curso de graduação? \\
\hline QD02 & Qual sua profissão? \\
\hline QD03 & Quantos anos de experiência na profissão? \\
\hline QC01 & Quais assuntos você gostaria de ter visto em sala de aula? \\
\hline QC02 & O quê de aula teórica você gostaria de ter visto em sala de aula? \\
\hline QC03 & O quê de aula prática você gostaria de ter visto em sala de aula? \\
\hline QC04 & Que tipo de ferramentas você gostaria de usar na disciplina? \\
\hline QC05 & Quais ambientes ou plataformas específicos você gostaria de ter utilizado na disciplina? \\
\hline QA01 & Quais os pontos fortes da disciplina? \\
\hline QA02 & Quais os pontos fracos da disciplina? \\
\hline QA03 & Quais as sugestões de melhoria para a disciplina? \\
\hline
\end{tabular}

A análise qualitativa deste trabalho foi inspirada nos procedimentos apresentados por Ferreira et al. (2018). Nessa análise, nós utilizamos procedimentos da metodologia Grounded Theory (Corbin e Strauss, 2014), a qual visa criar uma teoria a partir dos dados coletados e analisados sistematicamente, sendo composta por três fases: (1) codificação aberta, (2) codificação axial e (3) codificação seletiva.

Na codificação aberta, se executa uma quebra, análise, comparação, conceituação e categorização dos dados (Corbin e Strauss, 2014). Na codificação axial, associam-se as categorias às suas subcategorias, formando categorias mais relacionadas e densas. Por fim, na codificação seletiva, se identifica a categoria ou ideia central do estudo, correspondente à teoria na qual todas as categorias estão relacionadas. O processo de codificação finaliza quando nenhum novo dado adiciona novos conhecimentos ao processo de análise da categorização. Strauss e Corbin explicam que o pesquisador pode utilizar apenas alguns passos para atingir seu objetivo de pesquisa (Corbin e Strauss, 2014). Nessa pesquisa, apenas as fases 1 e 2 da Grounded Theory foram utilizadas para a identificação das categorias e suas relações. Adicionalmente, para evitar tendências nas análises, outro pesquisador revisou o resultado, para ampliar a qualidade dos resultados.

Algumas citações dos participantes foram capturadas para destacar aspectos das questões de opinião. Estes participantes estão identificados na pesquisa com a seguinte nomenclatura, para preservar a anonimidade: letra maiúscula "P” seguida por um número que corresponde à sequência de resposta do questionário.

\section{Resultados e Discussões}

O questionário foi aplicado em 2021.1, na turma de DTAE, do Programa de PósGraduação em Tecnologia Educacional (PPGTE), da Universidade Federal do Ceará. De um total de 19 alunos, 13 responderam o questionário. A Figura 1 apresenta algumas telas dos produtos de software produzidos durante a disciplina. Ao todo foram cinco equipes, das quais quatro escolheram desenvolver um aplicativo, e uma decidiu personalizar um ambiente já existente. As equipes possuíam perfis bem variados, porém alguns alunos possuíam experiência com programação, o que permitiu o desenvolvimento de aplicações em plataformas variadas. No caso, foram desenvolvidas aplicações web e móvel. Para modelagem, algumas equipes utilizaram o Figma. Os ambientes ou plataformas de programação e linguagens utilizados foram o Scratch, Node.js, Flutter e PHP. Apenas uma equipe não programou uma aplicação, atuando na customização do Moodle e WordPress para um ambiente para cursos de disciplinas e material didático.

As questões demográficas traçaram um perfil dos alunos que responderam ao questionário. QD01 apresentava o curso de graduação de quem respondeu, sendo que Pedagogia obteve 3 respostas, e os demais cursos apenas 1 . A maioria dos cursos era de V. $19 \mathrm{~N}^{\circ}$ 2, Dezembro, 2021 DOI: https://doi.org/10.22456/1679-1916.121224 RENOTE 
Licenciatura em alguma área, e apenas um curso era relacionado à Computação (Sistemas de Informação). QD02 apresentou a profissão, que não necessariamente é na área de formação do aluno, com a maioria das respostas sendo para professor (8). QD03 apontou a experiência do aluno em anos, sendo bastante variada, de 5 a 18 anos. A Figura 2 exibe as respostas para as questões demográficas.
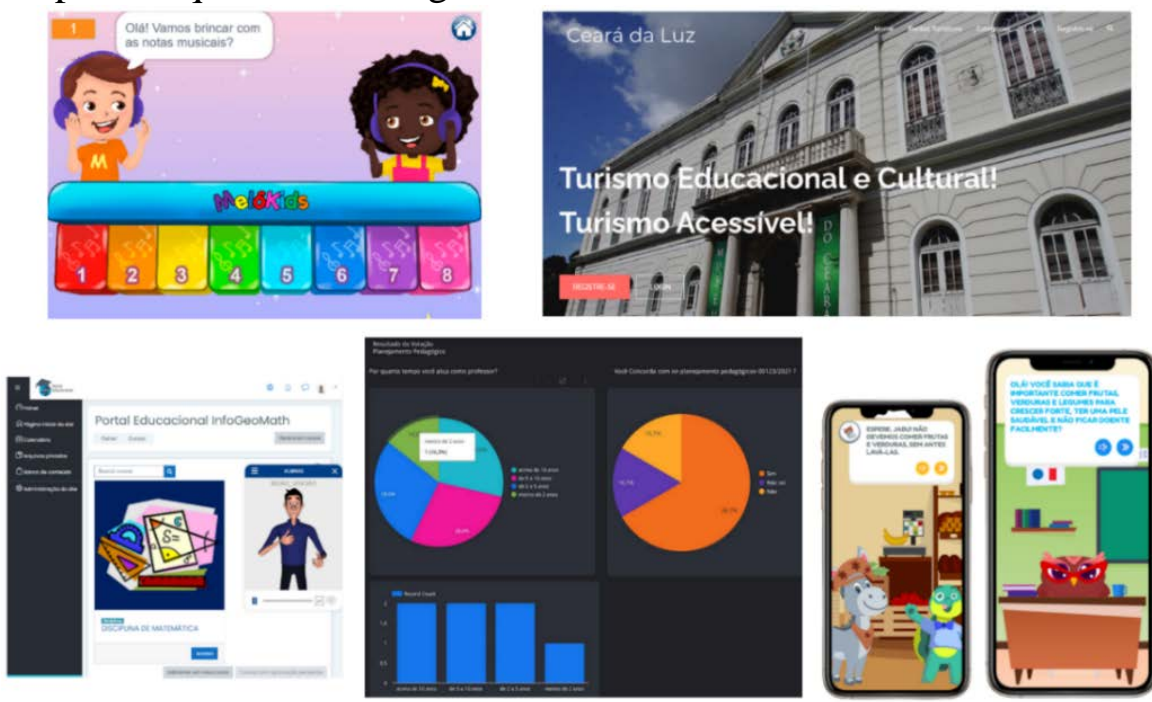

Figura 1 - Aplicações educacionais desenvolvidas na disciplina.

Como o perfil que mais se destacou foi o de professor, algumas análises estatísticas foram conduzidas para entender um melhor a distribuição dos alunos. Considerando apenas os alunos que são professores (8), calculou-se a média de experiência em anos, a variância e o desvio padrão, resultando em 9,37, 19,69 e 4,43, respectivamente. A média indicou um nível de experiência alto para os alunos em ensino. Quanto maior for a variância, mais distantes da média estarão os valores, e quanto menor for a variância, mais próximos os valores estarão da média. Ao considerar os extremos de experiência, verificou-se 5 e 17 anos. O desvio padrão indica o quanto confiável é esse o valor em relação à média, impactado pela quantidade baixa de respostas.
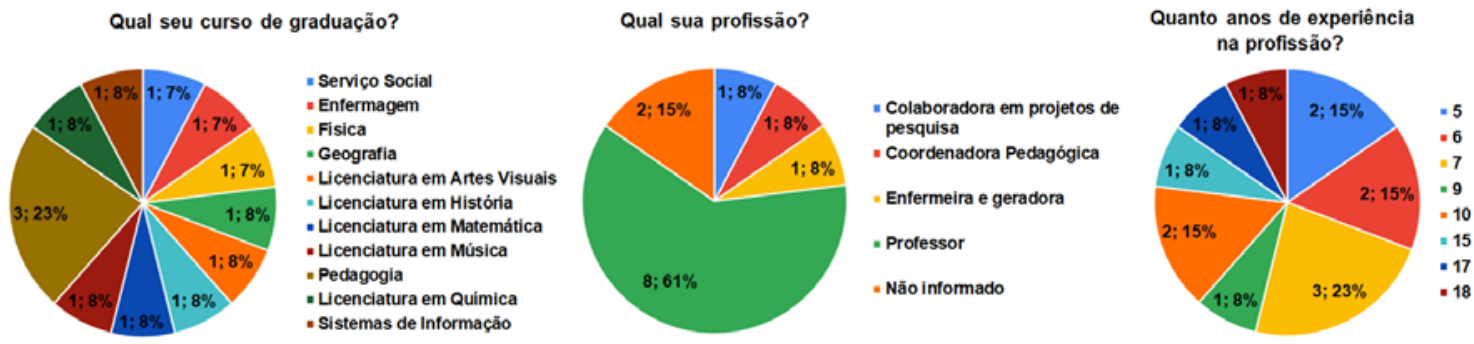

Figura 2 - Gráficos das questões demográficas.

As questões específicas sobre a disciplina permitiram saber a opinião dos alunos em relação a ferramentas e conteúdo. Em relação a quais assuntos o aluno gostaria de ter visto em sala de aula (QC01), as respostas variaram nas seguintes categorias, após um agrupamento conforme a leitura das respostas: Linguagens de programação, Aplicações web, Design e Jogos. O destaque foi para menções a HTML e CSS, principalmente pelo entendimento da grande importância das aplicações web na atualidade. Houve menções a assuntos que não faziam parte da ementa da disciplina, como edição de áudio e vídeo. Já QC02 foi em relação a o quê o aluno gostaria de ter visto de aula teórica. Muitos comentários foram sobre programação básica. Alguns sobre o estabelecimento de requisitos para uma aplicação, motivado por um pouco de Engenharia de Software V. $19 \mathrm{~N}^{\circ}$ 2, Dezembro, 2021 RENOTE 
ministrado em algumas aulas. QC03 verificou o quê de aula prática o aluno gostaria de ter visto em sala de aula. $\mathrm{O}$ foco foi em programação, mas para áreas diferentes, como dispositivos móveis, programação com blocos e aplicações educacionais. Também foi apontado que algumas ferramentas apresentadas em aula poderiam ter sido melhores exploradas com mais práticas, como o Scratch. Ainda assim, nessas questões houveram alunos que informaram que, tanto em teoria quanto na prática, se deram por satisfeitos com o conteúdo.

A Figura 3 reflete QC04, que destacou o tipo de ferramenta que os alunos gostariam de utilizar na disciplina. Como nesta questão havia a possibilidade de selecionar mais de um tipo de ferramenta, várias foram selecionadas pelos alunos. Ferramentas de modelagem foram as menos selecionadas. Isso pode indicar uma deficiência da disciplina, pois focou mais em programação/codificação do que pensar em requisitos, arquitetura ou comportamento. Essa pode ser uma oportunidade para as próximas edições da disciplina. Vídeo, imagem e som não fazem parte da ementa da disciplina, que é essencialmente desenvolver uma aplicação. Porém, algumas atividades possuíam como produto final a entrega de um vídeo de apresentação da ferramenta, para minimizar falhas nas apresentações. Isso pode ter influenciado essa alta quantidade de respostas. Por fim, ferramentas relacionadas à programação foram as mais citadas.

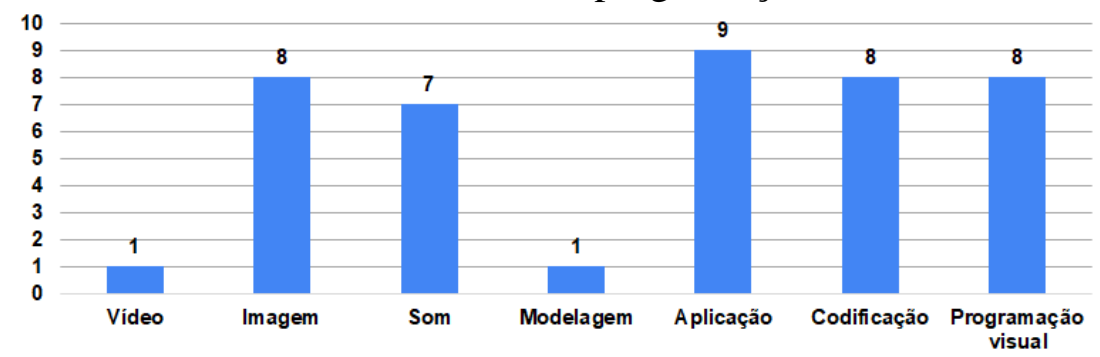

Figura 3 - Tipo de ferramenta que os alunos gostariam de utilizar na disciplina.

QC05 questionava quais ambientes ou plataformas específicos o aluno gostaria de ter utilizado na disciplina. Tais ambientes poderiam ser uma IDE (Integrated Development Environment - Ambiente de Desenvolvimento Integrado), por exemplo. A maioria foi em relação a ambientes de programação, por exemplo Scratch e Unity. Também houve menção ao Figma, uma ferramenta para modelagem de interfaces e navegabilidade em aplicativos. A maioria dos alunos nunca teve experiência com ferramentas de modelagem de sistemas nem com programação. Porém muitos destacaram ambientes mais direcionados para programação sem codificação explícita, como blocos.

As questões QA01, QA02 e QA03 foram analisadas por meio da Grounded Theory. A Tabela 3 descreve as categorias identificadas, e a Figura 4 exibe as categorias e suas relações. Neste trabalho, 7 categorias foram identificadas, dispostas em ordem decrescente de citações: Didática (29), Conteúdo (16), Suporte (14), Compreensão (12), Valor (12), Experiência (8), Tecnologia (8), Opinião (7), Atividades (4) e Metodologia (2). Além disso, 8 relacionamentos entre as categorias foram identificados.

A categoria Característica possuiu apenas uma relação mais explícita, com a categoria Sentimento, reforçado pelo discurso de P10 com “A disciplina foi excelente, $o$ trabalho proposto ajudou a expandir os conhecimentos”. A categoria Orientação também possuiu apenas uma relação, com a categoria Sentimento, apontado com a resposta de P1 em "A ideia do projeto foi bem interessante, aprendemos bastante uns com os outros". Esta relação foi de causa, onde a orientação provocava sentimentos nos alunos, e no caso foram positivos. Em relação à categoria Gestão, a única relação foi com Metodologia, que é de se esperar devido ao impacto da estratégia adotada na condução da disciplina 
com a gestão acadêmica e processos, ressaltado pelo comentário de P9 em "Algo bem legal foi utilizar os conceitos de engenharia de software para gerenciar o projeto, ... e no fim, todos conseguiriam trabalhar melhor e evitar as ilhas de conhecimento na equipe”.

Tabela 3 - Categorias identificadas na pesquisa.

\begin{tabular}{|l|l|}
\hline Categoria & Descrição \\
\hline Característica & Características de disciplina. \\
\hline Conteúdo & Ementa, material didático, exercícios, conteúdo da disciplina de maneira geral. \\
\hline Gestão & $\begin{array}{l}\text { Forma de condução da disciplina, gestão acadêmica de maneira geral, planejamento e } \\
\text { replanejamento da disciplina, relação com cronograma da disciplina, alocação de recursos. }\end{array}$ \\
\hline Metodologia & Metodologias, técnicas e estratégias adotadas na disciplina. \\
\hline Orientação & Suporte dos professores aos alunos, em relação a tarefas, produtos e projetos. \\
\hline Sentimento & $\begin{array}{l}\text { O sentimento dos alunos em relação a algum aspecto da disciplina. Sentimentos positivos ou } \\
\text { negativos. }\end{array}$ \\
\hline Tecnologia & $\begin{array}{l}\text { Ferramentas, ambientes e plataformas utilizados na disciplina para atividades acadêmicas e } \\
\text { desenvolvimento. }\end{array}$ \\
\hline
\end{tabular}

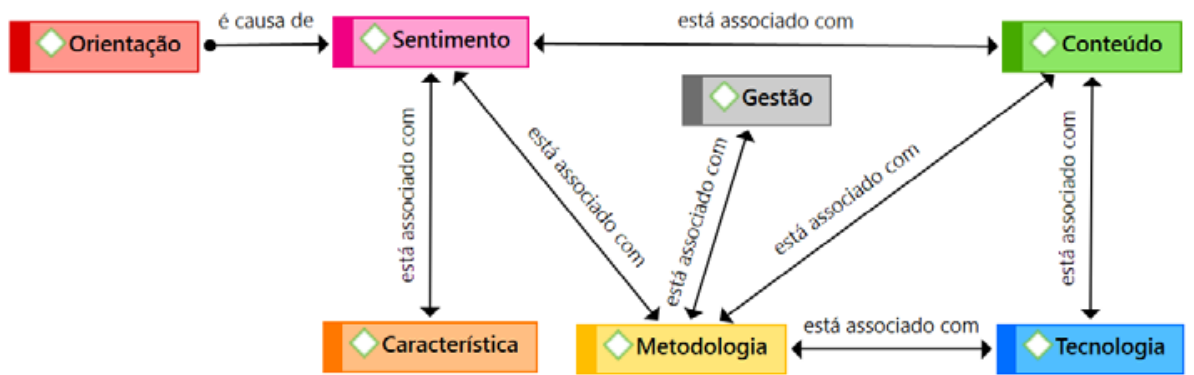

Figura 4 - Categorias e relações identificadas após a análise qualitativa.

A categoria Metodologia foi uma das que obteve mais relações. Há uma forte relação com Gestão, pois muitas vezes a forma como a disciplina é conduzida depende da metodologia (e vice-versa). Isso foi reforçado por P9 em "Sendo assim, os trabalhos em grupos terminou ficando meio que sobrecarregando um ou dois membros pelo fato de apenas eles dominarem o desenvolvimento de software, sendo esta a parte mais árdua do projeto". Em relação à Tecnologia, a metodologia estava associada à maneira na qual ela poderia ser aplicada para que a metodologia na disciplina fosse mais adequada, principalmente quanto às ferramentas de programação, reforçado por P7 com “Ausência de um diagnóstico do perfil da turma para uso de ferramentas tecnológicas”. Tecnologia muitas vezes focou na plataforma de desenvolvimento.

A categoria Conteúdo destacou a importância no conhecimento e nível de programação e de ferramentas de desenvolvimento dos alunos, para a plena execução dos projetos, reforçado pelo comentário de P12 com "Acredito que abordar conceitos de programação ou ferramentas simples que possa contribuir para a formação dos alunos" e de P9 com "Como o público alvo é muito amplo (alunos com e sem conhecimento em programação) poderia ter escolhido uma ou no máximo duas plataformas no início do semestre e irmos estudando apenas ela".

Por fim, a categoria Sentimento revelou as impressões dos alunos diante de certas situações, como a programação e cobranças de prazos, e proporcionaram sentimentos diretos das atividades. P1 respondeu o seguinte: "Algumas explicações sobre os conceitos de algoritmos foram bem complicados de compreender para quem não tinha nenhum conhecimento". P12 destacou um aspecto técnico em "Linguagem da disciplina, diferente da nossa realidade”. E P10 retornou uma visão geral da disciplina com “A disciplina foi excelente, o trabalho proposto ajudou a expandir os conhecimentos”.

Em relação aos pontos fortes da disciplina, os maiores destaques foram: didática, sugestões de melhorias dos protótipos, empatia dos professores, trabalho em equipe, V. $19 \mathrm{~N}^{\mathrm{o}}$ 2, Dezembro, 2021 RENOTE 
compromisso da equipe, flexibilidade no projeto, aplicação prática da disciplina na entrega dos produtos educacionais e interatividade. Dicas de ferramentas, principalmente de programação para iniciantes, foram mencionadas, possibilitando os que nunca viram programação aprender mais sobre o assunto. Por fim, aspectos de interdisciplinaridade surgiram como incentivos para o trabalho em equipe de profissionais de diferentes áreas.

Alguns pontos fracos da disciplina foram listados. A maioria foi relacionado ao ensino de programação para não programadores ou pessoas que nunca tiveram contato com desenvolvimento de sistemas. Explicações às vezes foram densas demais, o que prejudicava o entendimento para quem não possuía base de lógica. Devido à pandemia da COVID-19, não ocorreram aulas práticas presenciais, e isso foi destacado. A dependência do projeto de alguns membros da equipe, devido a um maior conhecimento em programação, se tornou evidente. Por fim, a ausência de um diagnóstico do perfil da turma para uso de ferramentas tecnológicas, e identificar quais seriam as mais adequadas e necessidades de treinamento.

Diversas sugestões de melhoria para a disciplina foram apontadas pelos alunos. Percebeu-se um interesse dos alunos por práticas de desenvolvimento, especificamente conceitos de Engenharia de Software como requisitos e análise. Isso foi ministrado de maneira geral em uma aula, o que não foi suficiente na visão dos alunos. Uma sugestão relacionada a esse aspecto foi modelar em alguma ferramenta e desenvolver em outra, para identificar a transição da ideia para a prática. Além disso, apontou-se que a escolha de plataformas para o desenvolvimento e criação de pequenos exemplos a cada aula auxiliaria na fixação de conceitos de desenvolvimento de software e na sua prática. Exemplos de produtos educacionais que poderiam ser desenvolvidos e respectivas apresentações deles também foi uma sugestão pertinente.

A ementa da disciplina é ampla. Isso torna impossível que alunos conheçam sobre tudo e ainda sejam capazes de realizar o desenvolvimento de um sistema passando por todas as fases de seu processo e tendo tempo hábil de refletir a cada etapa. Isto pode, claramente, dificultar o percurso do aluno no processo de desenvolvimento.

Analisando apenas em relação aos trabalhos relacionados identificados neste trabalho, poucos desenvolveram aplicações educacionais. Jogos são bastante utilizados, sendo uma boa estratégia para a aplicação na educação. Na disciplina, alguns jogos foram desenvolvidos. Alguns trabalhos relacionados focaram em aplicações web, outros em aplicações para dispositivos móveis. A portabilidade entre plataformas diferentes é um aspecto interessante para a disseminação da aplicação e da ideia educacional projetada. Por fim, muitos trabalhos relatam experiências com programação com blocos, muitos utilizando o Scratch e o APP Inventor. Tais ambientes auxiliam no ensino de lógica de programação e facilitam o foco na aplicação, ajudando alunos que não possuem experiência em programação a desenvolverem suas próprias aplicações.

\section{Conclusões}

A disciplina teve cinco aplicações educacionais desenvolvidas e apresentadas pelos alunos, atingindo o objetivo de prover experiência de desenvolvimento de aplicações educacionais. O uso de tecnologias foi bem diversificado, variando de ferramentas de modelagem a linguagens de programação. Percebeu-se que tecnologias são essenciais, mas há necessidade de dedicação para aprendizado, o que foi sentido na disciplina. As principais conclusões deste trabalho foram: reconhecimento da dificuldade no desenvolvimento para quem não possui formação em programação, necessidade de se gerenciar bem a disciplina para que a metodologia seja eficaz, e os alunos perceberam a pressão pelo cumprimento dos prazos, o que em equipes interdisciplinares pode ser ainda 
mais difícil de ser atendido.

Apesar da existência de muitos comentários indicando dificuldades com o desenvolvimento de aplicações, algumas citações foram na direção oposta, reconhecendo o esforço dos docentes, como no comentário de P13 citando a condução da disciplina: “Boa condução dos professores, ótimo domínio teórico e técnico" e no de parabenizando o esforço com P5 "Parabéns aos professores pela condução da disciplina. Foi excelente.”. Isso reforça que mesmo com dificuldades, houve reconhecimento. O aprendizado para ambos papéis neste ambiente, discentes e docentes, e a melhoria contínua é uma meta sempre a ser perseguida.

Como trabalhos futuros, pretende-se avaliar a qualidade da didática e o aprendizado. A qualidade dos produtos também é um aspecto a ser analisado, mas isso requer mais experiência tanto dos alunos quanto dos professores, além do desafio de executar tal análise dentro de uma disciplina semestral. Uma análise da metodologia aplicada pelos professores também pode ser uma boa fonte de pesquisa, podendo ser adotada uma metodologia mais genérica, mas que seja mais adequada ao ensino de programação. Por fim, o desenvolvimento de produtos educacionais pode ser melhor direcionado, com exemplos mais reais, e temáticas pré-definidas.

\section{Referências Bibliográficas}

ALMEIDA, W. I. S.; JÚNIOR, A. F. S. Ensino-Aprendizagem com Abordagem Colaborativa: aliando técnica pedagógica com Tecnologias Digitais de Informação e Comunicação. In: XXVI Workshop de Informática na Escola (WIE 2020). 2020.

BASTOS, C. A. R.; SIQUEIRA, S. W. M. Repensando o Ensino com Novas Tecnologias, Design Thinking e Experiência do aluno: Um Estudo Qualitativo com base em Formação Docente. Revista Brasileira de Informática na Educação - RBIE. v.28. 2020.

CORBIN, J.; STRAUSS, A. Basics of Qualitative Research: Techniques and Procedures for Developing Grounded Theory. Thousand Oaks: SAGE Publications, 4th edition. 2014.

COUTINHO, E. F.; GOMES, G. A. M.; JOSE, M. L. A. Applying design thinking in disciplines of systems development. In: 8th Euro American Conference on Telematics and Information Systems (EATIS). 2016.

FERREIRA, T.; VIANA, D.; FERNANDES, J.; SANTOS, R. Identifying emerging topics and difficulties in software engineering education in brazil. In: XXXII Brazilian Symposium on Software Engineering, SBES '18. 2018.

FONTOURA, J. S. D. A.; PROCASKO, J. C. R. O Mestrado Profissional em Informática na Educação do IFRS: Temas de Pesquisa, Objetos de Investigação e Produtos Privilegiados. RENOTE - Revista Novas Tecnologias na Educação. v.17, n.3. 2019.

GIL, A. C. Como elaborar projetos de pesquisa. 4. ed. São Paulo: Atlas, 2008.

GUARDA, G. F.; CUNHA, L. R. R.; GONÇALVES, C. S. Uso de Aplicativos Educacionais - Experiências com Aprendizagem Criativa na Educação Básica. In: XXV Workshop de Informática na Escola (WIE 2019). 2019.

MICHELS, A. B.; DANILEVICZ, A. M. F.; ARAGÓN, R. Tecnologias no trabalho docente: um olhar para o processo cognitivo de construção de estratégias pedagógicas. RENOTE - Revista Novas Tecnologias na Educação. v.19, n.1. 2021.

SONEGO, A.; RODRIGUES, A.; BEHAR, P. A. Aplicativos educacionais na formação de professores. RENOTE - Revista Novas Tecnologias na Educação. v.18, n.1. 2020.

SOUZA, E. P.; SOUSA, A. S.; MOURA, L. S. Desenvolvimento de aplicativos na/para a educação pública: uma parceria entre estudantes do ensino médio e graduandos. In: XXV Workshop de Informática na Escola (WIE 2019). 2019. 